\title{
MELAS in a Walk-in Customer
}

\author{
Josef Finsterer ${ }^{1}$
} ${ }^{1}$ Neurological Department, Krankenanstalt Rudolfstiftung, Vienna,
Austria

J Neurosci Rural Pract 2019;10:725-727

Mitochondrial encephalopathy, lactic acidosis, and strokelike episodes (MELAS) syndrome is a rare mitochondrial disorder (MID) predominantly due to mutations in mtDNA genes. ${ }^{1} \mathrm{~A}$ hallmark of the disease is the stroke-like episode (SLE), which is the clinical manifestation of a stroke-like lesion (SLL) on imaging. ${ }^{2}$ Here, we present the case of an adult, polymorbid female who was referred for management of epilepsy after a first generalized tonic-clonic seizure.

The patient is a 63-year-old female, height $155 \mathrm{~cm}$, weight $51 \mathrm{~kg}$, who presented 3 days after the first generalized tonicclonic seizure in her life. Due to epileptiform discharges on electroencephalogram (EEG), recorded on the day of the seizure, valproic acid (VPA) $1,000 \mathrm{mg} / \mathrm{d}$ was started. Follow-up EEG, 2 days after initiation of VPA, did no longer show epileptiform discharges. Cerebral magnetic resonance imaging (MRI) on the day of the seizure surprisingly revealed a hyperintense lesion on diffusion-weighted imaging (DWI) in a right occipito-temporal distribution, which was slightly hyperintense on apparent diffusion coefficient (ADC) maps, thus suggesting a vasogenic edema in a nonvascular distribution ( - Fig. 1). Creatine kinase (CK) was slightly elevated $(200 \mathrm{U} / \mathrm{L}, n<170 \mathrm{U} / \mathrm{L})$, and there was mild lactic acidosis (serum lactate: $2.4 \mathrm{mmol} / \mathrm{L}, n<2.1 \mathrm{mmol} / \mathrm{L}$ ). Creatinine was $4.66 \mathrm{mg} / \mathrm{dL}(n=0.5-0.9 \mathrm{mg} / \mathrm{dL})$ and the glomerular filtration rate was $14 \mathrm{~mL} / \mathrm{min} / 1.7 \mathrm{~m}^{2}\left(n=>90 \mathrm{~mL} / \mathrm{min} / 1.7 \mathrm{~m}^{2}\right)$.
Address for correspondence Josef Finsterer, MD, PhD, Postfach 20, 1180 Vienna, Austria (e-mail: fifigs1@yahoo.de).

The individual history was positive for migraine since teenage, arterial hypertension since years, benign right-sided ovarian cysts diagnosed at the age of 33 years, disc extraction L5/S1, long-term nicotine misuse, and chronic obstructive pulmonary disease (COPD). At the age of 62 years, hyperaldosteronism, hypocorticism (reduced adrenocorticotropic hormone), multiple lung cysts, a small hiatal hernia, and a multifocal urothelial carcinoma of the right ureter and the right kidney pelvis, treated by nephrectomy, were detected. At the age of 63 years, left suprarenal adenoma, treated with laparoscopic adrenalectomy, myocardial infarction, requiring implantation of a drug-eluting stent into the right coronary artery, hemangioma of the liver, urothelial carcinoma of the left kidney, extensive diverticulosis, polyposis of the colon, and adenocarcinoma of the sigma requiring combined colectomy and left-sided nephrectomy were diagnosed. Since surgery, she required hemodialysis.

Clinical neurologic examination revealed hypertelorism, bilateral ptosis with right-sided predominance, lid edema, bilaterally mild ophthalmoparesis with double vision when looking into any direction, hypoacusis bilaterally, quadruparesis M4- to M5-, generalized wasting, reduced tendon reflexes on the upper limbs, missing tendon reflexes on the lower limbs, and bradydiadochokinesia bilaterally. The last medication included acetyl-salicylic acid, clopidogrel, amlodipine,
DWI
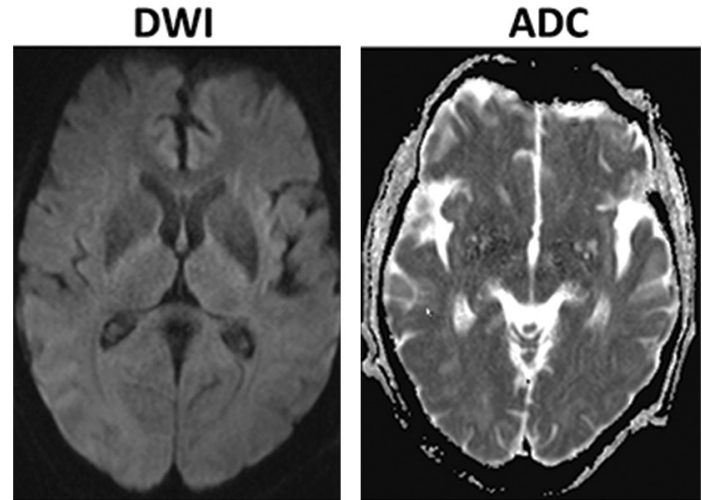

\section{TIRM}

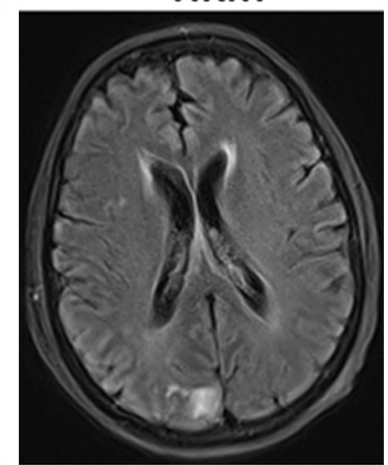

Fig. 1 Multimodal MRI on the day of the first ever generalized tonic-clonic seizure revealed a hyperintensity on DWI in the right parieto-occipital region in a nonvascular distribution. This lesion was slightly hyperintense on ADC. MRI, magnetic imaging resonance; DWI, diffusion weighted imaging; ADC, apparent diffusion coefficient; TRIM, TR independent multi-slice imaging.

DOI https://doi.org/ 10.1055/s-0039-1700618 ISSN 0976-3147.
License terms

() (1) $\ominus \circledast$ 
doxazosin, bisoprolol, simvastatin, citalopram, esomeprazol, fenoterol plus ipratropium bromide, dronabinol, and VPA. ProBNP was $27,000 \mathrm{ng} / \mathrm{L}(n<247 \mathrm{mg} / \mathrm{L})$. Electrocardiogram (ECG) showed an atrioventricular (AV)-block 1. After combined left nephrectomy and colectomy, an expanding lesion in the lung and the liver was found, being interpreted as pulmonary and hepatic metastases. A palliative care setting was adopted and further diagnostic work-up for suspected MID suspended.

The patient is interesting because a first tonic-clonic seizure led to the detection of a SLL and the suspicion of MELAS. Although SLLs may occur also together with other mitochondrial and nonmitochondrial conditions, ${ }^{3}$ SLLs most frequently and consistently occur in $>90 \%$ of MELAS patients. ${ }^{1}$ Other MIDs in which SLEs/SLLs have been reported include myoclonus epilepsy with ragged-red fibers (MERRF), Leigh syndrome, Kearns-Sayre syndrome (KSS), chronic progressive external ophthalmoplegia (CPEO), Leber's hereditary optic neuropathy (LHON), polymerase gamma 1 (POLG1)-related MIDs, coenzyme-Q deficiency, and Saguenay-Lac-Saint-Jean syndrome. ${ }^{4}$ The SLL in the described patient occurred in a typical localization and presented with typical features on multimodal MRI, that is why other causes of the lesion were excluded.

SLLs manifest clinically as SLEs, frequently associated with seizures. It is even hypothesized that epileptiform discharges trigger SLLs. ${ }^{5}$ The second hypothesis, the vascular hypothesis, is not suitable due to the nonvascular distribution of SLL. The third hypothesis, the metabolic hypothesis, does not sufficiently explain the development of a SLL. ${ }^{1}$ There was no indication for previous stroke or a current cytotoxic lesion in the presented patient and MRA did not reveal a significant stenosis, dissection, or an aneurysm of any intracerebral or extracranial artery. Possibly neurons become hyper-excitable due to the metabolic defect and react to epileptiform stimuli by uncontrolled discharges. Regression of SLLs on imaging without structural sequelae in the majority of the cases and rarity of permanent structural lesions, such as white matter lesions (WMLs), cysts, laminar cortical necrosis, atrophy, or the "toenail sign," favor the epileptic hypothesis.

Though diagnosing MELAS requires the detection and confirmation of a pathogenic mtDNA variant, MELAS was suspected in the presented patient due to the presence of the SLL and the multiorgan nature of the phenotype with typical manifestations of a MID ( $\mathbf{\text { Table }} \mathbf{1}){ }^{6}$ Arguments for MELAS in the patient are short stature, hypertelorism, the SLL, hypoacusis, ptosis, ophthalmoparesis, quadruparesis, diverticulosis, polyposis, renal insufficiency, heart failure, AV-block 1, lung cysts and ovarian cysts, hemangioma in the liver, suprarenal adenoma, and lactic acidosis (- Table 1) $)^{7.8}$ A further strong argument for a MID is the occurrence of four neoplasms (suprarenal adenoma, two urothelial carcinoma, colonic carcinoma), as has been previously reported in genetically confirmed MIDs. ${ }^{9}$

In conclusion, this case shows that patients with a first generalized tonic-clonic seizure require multimodal MRI, that ischemic stroke needs to be delineated from SLEs, and that MIDs may manifest as mitochondrial multiorgan disorder syndrome (MIMODS). ${ }^{10}$ An increased frequency of
Table 1 Phenotype features of the presented patient and in the literature

\begin{tabular}{|c|c|c|c|}
\hline Feature & $\begin{array}{l}\text { Presented } \\
\text { patient }\end{array}$ & $\begin{array}{l}\text { Previous } \\
\text { reports }\end{array}$ & Reference \\
\hline Lactic acidosis & $x$ & $x$ & 11 \\
\hline Seizures & $x$ & $x$ & 1 \\
\hline SLE & $x$ & $x$ & 1 \\
\hline Ptosis & $x$ & $\mathrm{v}$ & 12 \\
\hline $\begin{array}{l}\text { Ophthalmopa- } \\
\text { resis }\end{array}$ & $x$ & v & 6 \\
\hline Quadruparesis & $x$ & $x$ & 1 \\
\hline Short stature & $x$ & $x$ & 1 \\
\hline Dysmorphism & $x$ & $x$ & 13 \\
\hline $\begin{array}{l}\text { Renal } \\
\text { dysfunction }\end{array}$ & $x$ & $x$ & 14 \\
\hline Hypertelorism & $x$ & $x$ & 15 \\
\hline AV-block 1 & $x$ & $x$ & 16 \\
\hline Neuropathy & $x$ & $x$ & 1 \\
\hline Neoplasm & $x$ & $x$ & 17 \\
\hline $\begin{array}{l}\text { Pituitary } \\
\text { adenoma }\end{array}$ & $x$ & No & Not reported \\
\hline Hypocorticism & $x$ & No & Not reported \\
\hline Ovarian cysts & $x$ & No & Not reported \\
\hline $\begin{array}{l}\text { Liver } \\
\text { hemangioma }\end{array}$ & $x$ & No & Not reported \\
\hline $\begin{array}{l}\text { Suprarenal } \\
\text { adenoma }\end{array}$ & $x$ & No & Not reported \\
\hline Lung cysts & $x$ & No & Not reported \\
\hline Diverticulosis & $x$ & No & Not reported \\
\hline Polyposis & $x$ & No & Not reported \\
\hline
\end{tabular}

Abbreviations: SLE, stroke-like episode; AV, atrioventricular.

neoplasms may indicate a MID. If walk-in clients are stigmatized as not worthy of note, they may nonetheless become noteworthy if managed thoroughly.

\section{Authors' Contributions}

All authors contributed equally.

Note

Informed consent was obtained from the patient.

Funding

None.

Conflict of Interest

None declared.

\section{References}

1 El-Hattab AW, Almannai M, Scaglia F, MELAS. In: Adam MP, Ardinger HH, Pagon RA, Wallace SE, Bean LJH, Stephens K, eds. GeneReviews ${ }^{\circledR}$. Seattle, WA: University of Washington; 2001:1993-2019

2 Finsterer J. Stroke and stroke-like episodes in muscle disease. Open Neurol J 2012;6:26-36 
3 Finsterer J. Peculiarities of stroke-like lesions on MRI. Eur J Radiol Open 2019;6:60-61

4 Finsterer J. Mitochondrial metabolic stroke: phenotype and genetics of stroke-like episodes. J Neurol Sci 2019;400:135-141

5 Fryer RH, Bain JM, De Vivo DC. Mitochondrial encephalomyopathy lactic acidosis and stroke-like episodes (melas): a case report and critical reappraisal of treatment options. Pediatr Neurol 2016;56:59-61

6 Hansrote S, Croul S, Selak M, Kalman B, Schwartzman RJ. External ophthalmoplegia with severe progressive multiorgan involvement associated with the mtDNA A3243G mutation. J Neurol Sci 2002;197(1-2):63-67

7 Finsterer J, Frank M. Gastrointestinal manifestations of mitochondrial disorders: a systematic review. Therap Adv Gastroenterol 2017;10(1):142-154

8 Finsterer J, Zarrouk-Mahjoub S. Mitochondrial vasculopathy. World J Cardiol 2016;8(5):333-339

9 Finsterer J, Frank M. Prevalence of neoplasms in definite and probable mitochondrial disorders. Mitochondrion 2016;29:31-34

10 Finsterer J, Zarrouk-Mahjoub S. Mitochondrial multiorgan disorder syndrome score generated from definite mitochondrial disorders. Neuropsychiatr Dis Treat 2017;13:2569-2579

11 Thambisetty M, Newman NJ. Diagnosis and management of MELAS. Expert Rev Mol Diagn 2004;4(5):631-644
12 van Rossum IA, ten Houten R. Unexceptional symptoms as expression of MELAS [article in Dutch]. Ned Tijdschr Geneeskd 2010;154:A2168

13 Feigenbaum A, Chitayat D, Robinson B, et al. The expanding clinical phenotype of the tRNA(Leu(UUR)) A->G mutation at np 3243 of mitochondrial DNA: diabetic embryopathy associated with mitochondrial cytopathy. Am J Med Genet 1996;62(4):404-409

14 Alcubilla-Prats P, Solé M, Botey A, Grau JM, Garrabou G, Poch E. Kidney involvement in MELAS syndrome: description of 2 cases. Med Clin (Barc) 2017;148(8):357-361

15 Pronicki M, Sykut-Cegielska J, Mierzewska H, et al. Diversity of clinical symptoms in A3243G mitochondrial DNA mutation (MELAS syndrome mutation) Med Sci Monit 2002;8(11):CR767-CR773

16 Niedermayr K, Pölzl G, Scholl-Bürgi S, et al. Mitochondrial DNA mutation "m.3243A>G"-Heterogeneous clinical picture for cardiologists ("m.3243A>G": a phenotypic chameleon). Congenit Heart Dis 2018;13(5):671-677

17 Ohno A, Mori A, Doi R, Yonenaga Y, Asano N, Uemoto S. Successful left hemihepatectomy and perioperative management of a patient with biliary cystadenocarcinoma, complicated with MELAS syndrome: report of a case. Surg Today 2010;40(9):878-882 